\title{
Severe Early Onset Obesity due to a Novel Missense Mutation in Exon 3 of the Leptin Gene in an Infant from Northwest India
}

\author{
(D) Devi Dayal ${ }^{1}$, (D) Keerthivasan Seetharaman ${ }^{1}$, (D) Inusha Panigrahi ${ }^{2}$, (D) Balasubramaniyan Muthuvel ${ }^{1}$, (D) Ashish Agarwal ${ }^{1}$ \\ 1 Postgraduate Institute of Medical Education and Research, Department of Pediatrics, Division of Pediatric Endocrinology, Chandigarh, India \\ 2 Postgraduate Institute of Medical Education and Research, Department of Pediatrics, Division of Genetic-Metabolic, Chandigarh, India
}

\begin{abstract}
What is already known on this topic?
Congenital leptin deficiency due to mutations of the leptin gene is a rare cause of early-onset obesity with less than 50 cases reported to date.
\end{abstract}

\section{What this study adds?}

This article presents an Indian infant with severe early-onset obesity caused by a novel mutation in the leptin gene.

\begin{abstract}
Monogenic obesity, caused by mutations in one of the genes involved in the control of hunger and satiety, is a rare cause of early onset obesity (EOO). The most common of the single gene alterations affect the leptin gene (LEP), resulting in congenital leptin deficiency that manifests as intense hyperphagia, EOO and severe obesity associated with hormonal and metabolic alterations. Only eight mutations of LEP associated with congenital leptin deficiency have been described in humans to date. In this study, we report a novel, homozygous, missense mutation in exon 3 of the LEP gene (chr7:127894610;c.298G > A) resulting in the amino acid substitution of asparagine for aspartic acid at codon 100 (p.Asp100Asn) in a 10-month-old infant who presented to us with severe hyperphagia and EOO. She was subsequently found to have low serum leptin concentrations. Additionally, a homozygous missense variation of unknown significance in exon 11 of Bardet-Biedl syndrome-1 gene (chr11:66291279; G>A; Depth 168x) was detected. Significant abnormalities of lipid parameters were also present in our patient. Both parents were thin but there was a family history suggestive of EOO in a paternal uncle and a cousin. In conclusion, we report the second patient from India with a novel mutation of the LEP gene associated with severe obesity.
\end{abstract}

Keywords: Congenital leptin deficiency, monogenic obesity, leptin gene, novel mutation, early onset obesity, India

\section{Introduction}

Severe early onset obesity (EOO) may be caused by alterations in genes that regulate appetite, body weight and energy homeostasis (1). The most common single-gene alterations that cause severe EOO include mutations in the leptin $(L E P)$, leptin receptor $(L E P R)$, preopiomelanocortin, prohormone convertase 1 or melanocortin 4 receptor genes, which together account for 3-5\% of non-syndromic cases (1). These genes are involved in the control of hunger and satiety through the leptin-melanocortin signaling pathway in the hypothalamus. Of these genes, the most commonly affected is the LEP gene. Homozygous mutations in LEP cause the recessively inherited congenital leptin deficiency which manifests as severe EOO (1). Other characteristic manifestations include impaired satiety, intense hyperphagia, a normal birth weight and rapid weight gain during early infancy (1). These children also develop several hormonal and metabolic abnormalities associated with obesity in older children and adults (2). In addition, they may have reduced T-cell number and function, resulting in increased predisposition to infections and high rates of mortality during childhood (3). After the first report of a frameshift mutation in LEP in two severely obese cousins
Address for Correspondence: Devi Dayal MD, Postgraduate Institute of Medical Education and Research, Department of Pediatrics, Division of Pediatric Endocrinology, Chandigarh, India

Phone: +91-172-2755657 E-mail: drdevidayal@gmail.com ORCID ID: orcid.org/0000-0002-3279-6002

This manuscript was presented as a poster in UPEK 2016 (Turkish National Pediatric Endocrinology Congress).

${ }^{\circ}$ Copyright 2018 by Turkish Pediatric Endocrinology and Diabetes Society

The Journal of Clinical Research in Pediatric Endocrinology published by Galenos Publishing House.
Conflict of interest: None declared Received: 13.10 .2017 Accepted: 29.11.2017 
from a consanguineous United Kingdom family of Pakistani origin (4), several other patients with frameshift, missense or deletion mutations in $L E P$ have been reported $(5,6,7,8$, $9,10,11,12,13,14,15,16,17)$. These reports have emanated from several countries and especially from regions with high rates of consanguinity. Approximately $80 \%$ of about 50 patients described in the literature so far come from Central Pakistan $(4,5,6,7,8)$. In this communication, we report a novel homozygous missense mutation in LEP associated with low serum leptin concentrations, hyperphagia and severe EOO in an infant from Northwest India.

\section{Case Report}

A 10-month-old girl was referred to our endocrine unit for evaluation of excessive and rapid weight gain. She was born at full term by normal vaginal delivery and weighed $3.0 \mathrm{~kg}$ [-0.52 standard deviation score (SDS)] at birth. She is the second child of healthy, non-obese parents with third degree consanguinity. There was no history to suggest gestational diabetes, hypertension, hypothyroidism or excess weight gain by mother during pregnancy. Parents noticed increased appetite at about two months of age. She started demanding feeds at half to one hourly intervals. Subsequently, there was a rapid gain in her weight to $9.5 \mathrm{~kg}(+3.14 \mathrm{SDS})$ at four months and $15 \mathrm{~kg}(+8.17 \mathrm{SDS})$ at six months of age. There was no history of lethargy, dryness of skin, constipation, excessive hair growth, seizures, visual or sleep disturbances. There was a history of EOO in a paternal uncle and a male cousin.

Physical examination revealed generalized body fat distribution, a rounded face and deep skinfolds (Figure 1A, 1B). There were no stigmata of a syndrome or underlying endocrinopathy, except acanthosis nigricans in axillae and neck folds (Figure 1C). The vital parameters were normal. Her weight was $19 \mathrm{~kg}(+7.38 \mathrm{SDS})$, length $71.0 \mathrm{~cm}(-0.24$ SDS) and body mass index $37.7 \mathrm{~kg} / \mathrm{m}^{2}$ (+10.94 SDS). Anthropometric calculations were done using the World Health Organizetion (WHO) Anthroplus software (version 1.0.4 WHO, Geneva, Switzerland). Ophthalmological evaluation did not show retinitis pigmentosa. Systemic examination was unremarkable.

Laboratory investigations revealed normal routine hematological and biochemical parameters, except for serum liver aminotransferases. The results of other laboratory evaluations are shown in Table 1. Abdominal ultrasound showed normal morphology of kidneys, a liver span of $12 \mathrm{~cm}$ (normal 6.3-9.6 cm) and features of hepatic steatosis. Magnetic resonance imaging of the brain, with fine cuts through the pituitary and hypothalamus, showed no abnormality. In view of intense hyperphagia followed by
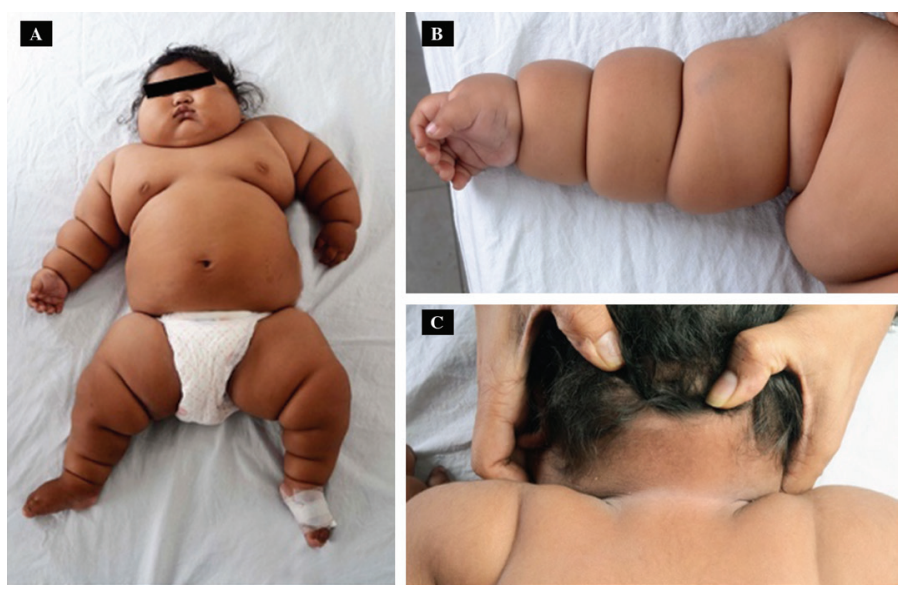

Figure 1. Clinical photographs of the patient showing A) generalized body fat distribution, B) deep skin folds and C) acanthosis nigricans

Table 1. Hormonal, metabolic and other laboratory results of the patient at presentation

\begin{tabular}{|c|c|c|}
\hline Variable & $\begin{array}{l}\text { Patient's } \\
\text { value }\end{array}$ & $\begin{array}{l}\text { Reference } \\
\text { range }\end{array}$ \\
\hline Fasting blood glucose (mg/dL) & 92 & $70-100$ \\
\hline Fasting C-peptide (ng/mL) & 4.08 & $1.1-4.4$ \\
\hline Fasting plasma insulin (mIU/L) & 18.56 & $2.6-24.9$ \\
\hline $\operatorname{HbA1c}(\%)$ & 5.4 & $4.0-5.8$ \\
\hline Plasma cortisol (nmol/L) & 473 & $171-536$ \\
\hline Plasma ACTH (pg/mL) & 8.0 & $5.0-60$ \\
\hline Triiodothyronine (ng/mL) & 2.56 & $0.8-2.0$ \\
\hline Thyroxine $(\mu \mathrm{g} / \mathrm{dL})$ & 11.20 & $4.8-12.7$ \\
\hline TSH ( $\mu \mathrm{IU} / \mathrm{mL})$ & 5.23 & $0.27-4.2$ \\
\hline Random growth hormone (ng/mL) & 0.44 & $0-2.5$ \\
\hline Luteinizing hormone (mIU/mL) & 0.100 & $<1-3.3$ \\
\hline Follicle-stimulating hormone (mIU/mL) & 3.38 & $<1-7.1$ \\
\hline Estradiol (pmol/L) & 5.0 & $0-<73.5$ \\
\hline Testosterone (nmol/L) & 0.087 & $<1.0$ \\
\hline 25-hydroxy vitamin D (ng/mL) & 7.87 & $20.0-40.0$ \\
\hline Parathyroid hormone (pg/mL) & 27.71 & $15-65$ \\
\hline Total cholesterol (mg/dL) & 129.2 & $150-200$ \\
\hline $\begin{array}{l}\text { Low-density lipoprotein cholesterol } \\
(\mathrm{mg} / \mathrm{dL})\end{array}$ & 51.7 & $0-130$ \\
\hline $\begin{array}{l}\text { High-density lipoprotein cholesterol } \\
(\mathrm{mg} / \mathrm{dL})\end{array}$ & 30.0 & $35-55$ \\
\hline Serum leptin (ng/mL) & 1.25 & $2.0-5.6$ \\
\hline Serum adiponectin (mg/mL) & 6.2 & $5.0-7.5$ \\
\hline Aspartate aminotransferase (U/L) & 53 & $3-30$ \\
\hline Alanine aminotransferase (U/L) & 89 & $7-45$ \\
\hline
\end{tabular}




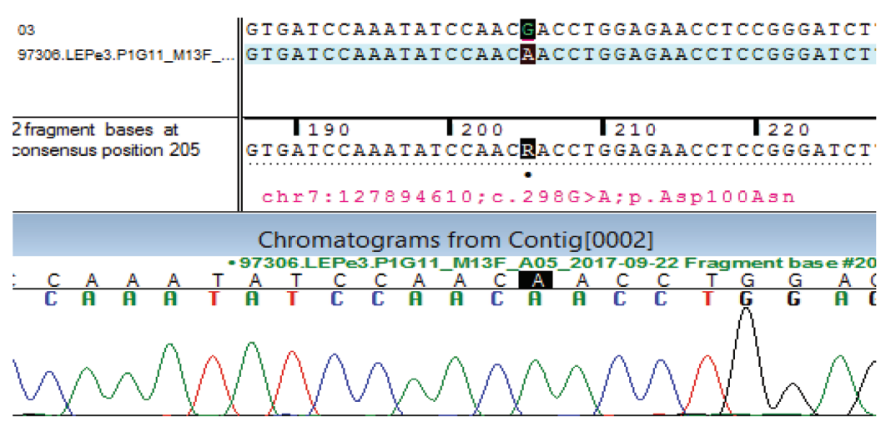

Figure 2. Sequence chromatogram showing homozygous missense mutation in exon 3 of the leptin gene (chr7:127894610;c.298G > A) resulting in the amino acid substitution of asparagine for aspartic acid at codon 100 (p.Asp100Asn)

rapid weight gain, early age of onset, family history of EOO and low level of circulating leptin, a diagnosis of monogenic obesity due to LEP gene mutation was considered. Written informed consent was obtained from the parents for conducting all laboratory studies and for publishing clinical information and photographs.

For genetic studies, genomic DNA extracted from blood was used to perform targeted gene capture using a custom capture kit on Illumina HiSeq 2000 sequencing platform (Illumina, California, USA). Sequencing identified a homozygous missense mutation in exon 3 of the LEP gene (chr7:127894610;c.298G > A) resulting in the amino acid substitution of asparagine for aspartic acid at codon 100 (p.Asp100Asn). Validation of the identified mutation was done by Sanger sequencing to exclude false positivity (Figure 2). The Asp100Asn variant lies in the functional domain of the leptin protein and has not been reported in the 1000 Genomes database. It has a minor allele frequency of $0.0008 \%$ in the Exome Aggregation Consortium (ExAC) database. The in silico predictions of the effect of the mutation are "probably pathogenic" by Polyphen-2 (HumDiv) and "pathogenic" by Sorting Intolerant From Tolerant, Log ratio test and MutationTaster2. The reference codon is conserved across species.

Sequencing also revealed a homozygous missense variation in exon 11 of Bardet-Biedl syndrome-1 (BBS1) gene (chr11:66291279; G>A; Depth 168x) resulting in amino acid substitution of isoleucine for valine at codon 346 (p.Val346Ile). This variant has a minor allele frequency of $0.16 \%$ and $0.1 \%$ in the 1000 Genomes and ExAC databases respectively. The in silico prediction of the effect of the mutation is "pathogenic" by only MutationTaster2. The reference codon is conserved across mammals. This BBS1 mutation is classified as a variant of uncertain significance based on the above evidence. Sanger sequencing of exon 3 of the LEP gene and exon 11 of BBS1 gene of the unaffected parents identified the same variations as in the index patient but with heterozygous inheritance.

\section{Discussion}

The majority of children with EOO have simple obesity (18). However, about $5 \%$ of all children with EOO may have monogenic obesity caused by mutations in one of the several genes involved in the regulation of appetite and body weight (1). Even rarer are the syndromic forms of EOO such as BBS, Prader-Willi syndrome and BeckwithWiedemann syndrome caused by genetic, epigenetic and genomic alterations (1). The most common and treatable form of monogenic obesity is due to mutations in the LEP gene manifesting as hyperphagia and rapid weight gain starting from early infancy (4). The clinical manifestations in the index patient were similar to the previously reported patients $(4,5,6,7,8)$. Additionally, our patient exhibited severe abnormalities of lipid parameters, usually found in patients with congenital leptin deficiency during late childhood or even adulthood, at 10 months of age (8). However, other common obesity-associated complications such as abnormalities of glucose homeostasis and blood pressure were not detected in our patient $(2,8)$. The mild elevation of serum aminotransferases was possibly related to hepatic steatosis commonly seen in patients with obesity and dyslipidemia (19).

The mutation (chr7:127894610;c.298G > A) in our patient that led to amino acid substitution of asparagine for aspartic acid at codon 100, has not been described previously. However, a different missense variation (Asp100Tyr) affecting the same codon has been reported (13). Interestingly, the affected patient had high circulating levels of mutant leptin (functional studies showed that leptin was biologically inactive) (13), unlike the characteristically absent or nearly absent circulating leptin in LEP gene mutations $(5,6,7,8)$. We presume that the low serum leptin concentrations secondary to the mutated $L E P$ gene resulted in severe hyperphagia and severe EOO in our patient. The serum concentrations of leptin were even lower than the recent local normative data for children (mean serum levels $1.4 \pm 0.5$, range $1.04-3.71 \mathrm{ng} / \mathrm{mL})(20)$.

Leptin is an important afferent, peripheral, humoral signal to the appetite-regulating network in the hypothalamus and affects food intake and energy expenditure. It is an important predictor of weight gain even during early infancy (21). Therefore, low levels of leptin or its biological inactivity resulting from mutations in LEP may disturb metabolic balance, leading to severe obesity and related metabolic disorders. Leptin replacement normalises these hormonal 
and metabolic alterations, suggesting that leptin deficiency or inactivity is the predominant determinant of obesity associated disorders in these patients $(3,9,13)$.

The finding of BBS1 gene mutation in our patient is intriguing. BBS is a known cause of a syndromic form of $\mathrm{EOO}$ and BBS proteins are required for LEPR signalling (22). However, leptin resistance rather than leptin deficiency is the characteristic finding in obese patients with BBS (23). The obesity usually manifests by $2-3$ years of age, unlike that found in patients with $L E P$ gene mutation which manifests in early infancy $(22,23)$. Furthermore, our patient did not show the usual BBS stigmata, such as retinitis pigmentosa, kidney dysfunction, polydactyly, behavioural problems and hypogonadism (22). Low levels of circulating leptin and compromised leptin signalling may account for the extreme obesity seen in this case.

A significant majority of the previously reported patients belong to consanguineous families of the Arain tribe, who live in the Central Punjab, Pakistan (5,6,7). Incidentally, our patient hails from a geographical area in Indian Punjab approximately 30 miles away from this location, where most patients so far described live $(5,6,7)$. Although families of the Arain community have a scattered presence across Northern India, including Punjab, their consanguinity rates are lower. Our patient does not belong to the Arain community, although third degree consanguinity was present. The first reported patient from India also came from North India (16). The geographic location points to either the operation of natural selection (carrier advantage) or random genetic drift (chance founder effects) for $L E P$ gene in this population.

The limitations of our study include the lack of functional studies to understand the mechanism of disease manifestations in the patient. Also, we could not screen other affected family members for the mutation detected in our patient.

In summary, we report an infant with congenital leptin deficiency due to a novel mutation of the LEP gene, manifesting as severe EOO and dyslipidemia. This is only the second case from India with LEP gene mutation in the published literature. In patients with EOO, identifying those with LEP gene mutations is important, as recombinant human leptin therapy offers substantial clinical benefits in these patients.

\section{Ethics}

Informed Consent: Written informed consent was obtained from the parents.

Peer-review: Externally peer-reviewed.

\section{Authorship Contribution}

Concept: Devi Dayal, Design: Devi Dayal, Data Collection or Processing: Keerthivasan Seetharaman, Balasubramaniyan Muthuvel, Ashish Agarwal, Analysis or Interpretation: Devi Dayal, Inusha Panigrahi, Literature Search: Devi Dayal, Keerthivasan Seetharaman, Writing: Devi Dayal.

Financial Disclosure: The authors declared that this study received no financial support.

\section{References}

1. Serra-Juhé C, Martos-Moreno GÁ, Bou de Pieri F, Flores R, González JR, Rodríguez-Santiago B, Argente J, Pérez-Jurado LA. Novel genes involved in severe early-onset obesity revealed by rare copy number and sequence variants. PLoS Genet 2017;13:e1006657.

2. Dayal D, Jain H, Attri SV, Bharti B, Bhalla AK. Relationship of high sensitivity C-reactive protein levels to anthropometric and other metabolic parameters in Indian children with simple overweight and obesity. J Clin Diag Res 2014;8:5-8. Epub 2014 Aug 20

3. Farooqi IS, Matarese G, Lord GM, Keogh JM, Lawrence E, Agwu C, Sanna V, Jebb SA, Perna F, Fontana S, Lechler RI, DePaoli AM, O’Rahilly S. Beneficial effects of leptin on obesity, T cell hyporesponsiveness, and neuroendocrine/metabolic dysfunction of human congenital leptin deficiency. J Clin Invest 2002;110:1093-1103.

4. Montague CT, Farooqi IS, Whitehead JP, Soos MA, Rau H, Wareham NJ, Sewter CP, Digby JE, Mohammed SN, Hurst JA, Cheetham CH, Earley AR, Barnett AH, Prins JB, O'Rahilly S. Congenital leptin deficiency is associated with severe early-onset obesity in humans. Nature 1997;387:903-908

5. Fatima W, Shahid A, Imran M, Manzoor J, Hasnain S, Rana S, Mahmood $\mathrm{S}$. Leptin deficiency and leptin gene mutations in obese children from Pakistan. Int J Pediatr Obes 2011;6:419-427. Epub 2011 Aug 19

6. Saeed S, Butt TA, Anwer M, Arslan M, Froguel P. High prevalence of leptin and melanocortin-4 receptor gene mutations in children with severe obesity from Pakistani consanguineous families. Mol Genet Metab 2012;106:121-126. Epub 2012 Mar 10

7. Saeed S, Bonnefond A, Manzoor J, Shabir F, Ayesha H, Philippe J, Durand E, Crouch H, Sand O, Ali M, Butt T, Rathore AW, Falchi M, Arslan M, Froguel P. Genetic variants in LEP, LEPR, and MC4R explain $30 \%$ of severe obesity in children from a consanguineous population. Obesity (Silver Spring) 2015;23:1687-1695. Epub 2015 Jul 14

8. Shabana, Hasnain S. The p. N103K mutation of leptin (LEP) gene and severeearlyonsetobesity in Pakistan. Biol Res 2016;49:23.

9. Paz-Filho G, Mastronardi C, Delibasi T, Wong ML, Licinio J. Congenital leptin deficiency: diagnosis and effects of leptin replacement therapy. Arq Bras Endocrinol Metabol 2010;54:690-697.

10. Andiran N, Celik N, Andiran F. Homozygosity for two missense mutations in the leptin receptor gene (P316:W646C) in a Turkmenian girl with severe early-onset obesity. J Pediatr Endocrinol Metab 2011;24:1043-1045.

11. Mazen I, El-Gammal M, Abdel-Hamid M, Amr K. A novel homozygous missense mutation of the leptin gene (N103K) in an obese Egyptian patient. Mol Genet Metab 2009;97:305-308. Epub 2009 Apr 9

12. Mazen I, Amr K, Tantawy S, Farooqi IS, El Gammal M. A novel mutation in the leptin gene (W121X) in an Egyptian family. Mol Genet Metab Rep 2014;1:474-476 
13. Wabitsch M, Funcke JB, Lennerz B, Kuhnle-Krahl U, Lahr G, Debatin KM, Vatter P, Gierschik P, Moepps B, Fischer-Posovszky P. Biologically inactive leptin and early-onset extreme obesity. N Engl J Med 2015;372:48-54.

14. Altawil AS, Mawlawi HA, Alghamdi KA, Almijmaj FF. A Novel Homozygous Frameshift Mutation in Exon 2 of LEP Gene Associated with Severe Obesity: A Case Report. Clin Med Insights Pediatr 2016;10:115-118.

15. Fischer-Posovszky P, von Schnurbein J, Moepps B, Lahr G, Strauss G, Barth TF, Kassubek J, Mühleder H, Möller P, Debatin KM, Gierschik P, Wabitsch M. A new missense mutation in the leptin gene causes mild obesity and hypogonadism without affecting $\mathrm{T}$ cell responsiveness. J Clin Endocrinol Metab 2010;95:2836-2840. Epub 2010 Apr 9

16. Thakur S, Kumar A, Dubey S, Saxena R, Peters AN, Singhal A. A novel mutation of the leptin gene in an Indian patient. Clin Genet 2014;86:391-393. Epub 2013 Dec 5

17. Zhao Y, Hong N, Liu X, Wu B, Tang S, Yang J, Hu C, Jia W. A novel mutation in leptin gene is associated with severe obesity in Chinese individuals. Biomed Res Int 2014;2014:912052. Epub 2014 Feb 23

18. Dayal D, Soni V, Das G, Bhunwal S, Kaur H, Bhalla AK. Longitudinal observations on growth patterns of obese infants: Developing country perspectives. Preliminary study. Pediatria Polska 2017;92:397-400.
19. Kamble R, Sodhi KS, Thapa BR, Saxena AK, Bhatia A, Dayal D, Khandelwal N. Liver acoustic radiation force impulse (ARFI) in childhood obesity: comparison and correlation with biochemical markers. J Ultrasound 2016;20:33-42.

20. Tenneti N, Dayal D, Sharda S, Panigrahi I, Didi M, Attri SV, Sachdeva N, Bhalla AK. Concentrations of leptin, adiponectin and other metabolic parameters in non-obese children with Down syndrome. J Pediatr Endocrinol Metab 2017;30:831-837.

21. Treviño-Garza C, Estrada-Zúñiga CM, Mancillas-Adame L, VillarrealMartínez L, Villarreal-Pérez JZ, Rodríguez-Balderrama I, Montes-Tapia FF, de la O Cavazos ME. Adding Multiple Adipokines into the Model do not Improve Weight Gain Prediction by Leptin Levels in Newborns. J Clin Res Pediatr Endocrinol 2016;8:321-324. Epub 2016 Apr 18

22. Priya S, Nampoothiri S, Sen P, Sripriya S. Bardet-Biedl syndrome: Genetics, molecular pathophysiology, and disease management. Indian J Ophthalmol 2016;64:620-627.

23. Feuillan PP, Ng D, Han JC, Sapp JC, Wetsch K, Spaulding E, Zheng YC, Caruso RC, Brooks BP, Johnston JJ, Yanovski JA, Biesecker LG. Patients with Bardet-Biedl Syndrome Have Hyperleptinemia Suggestive of Leptin Resistance. J Clin Endocrinol Metab 2011;96:528-535. Epub 2011 Jan 5 